\title{
How to predict hydrological effects of local land use change: how the vegetation parameterisation for short rotation coppices influences model results
}

\author{
F. Richter ${ }^{1}$, C. Döring ${ }^{1}$, M. Jansen ${ }^{1}$, O. Panferov ${ }^{2,3}$, U. Spank ${ }^{4}$, and C. Bernhofer ${ }^{4}$ \\ ${ }^{1}$ Department of Soil Science of Temperate Ecosystems, Georg-August-Universität Göttingen, Büsgenweg 2, \\ 37077 Göttingen, Germany \\ ${ }^{2}$ Department of Bioclimatology, Georg-August-Universität Göttingen, Büsgenweg 2, 37077 Göttingen, Germany \\ ${ }^{3}$ Institute of Climatology and Climate Protection, University of Applied Sciences, Bingen am Rhein, Berlinstr. 109, \\ 55411 Bingen am Rhein, Germany \\ ${ }^{4}$ Institute of Hydrology and Meteorology, Technische Universität Dresden, Pienner Str. 23, 01737 Tharandt, Germany
}

Correspondence to: F. Richter (falk.richter@forst.uni-goettingen.de)

Received: 1 December 2014 - Published in Hydrol. Earth Syst. Sci. Discuss.: 13 January 2015

Revised: 15 June 2015 - Accepted: 9 July 2015 - Published: 7 August 2015

\begin{abstract}
Among the different bioenergy sources, short rotation coppices (SRC) with poplar and willow trees are one of the promising options in Europe. SRC provide not only woody biomass but also additional ecosystem services. However, a known shortcoming is the potentially lower groundwater recharge caused by the potentially higher evapotranspiration demand compared to annual crops. The complex feedbacks between vegetation cover and water cycle can be only correctly assessed by application of well-parameterised and calibrated numerical models. In the present study, the hydrological model system WaSim (Wasserhaushalts-SimulationsModel) is implemented for assessment of the water balance. The focus is the analysis of simulation uncertainties caused by the use of guidelines or transferred parameter sets from scientific literature compared to "actual" parameterisations derived from local measurements of leaf area index (LAI), stomatal resistance (Rsc) and date of leaf unfolding (LU). The analysis showed that uncertainties in parameterisation of vegetation lead to implausible model results. LAI, Rsc and LU are the most sensitive plant physiological parameters concerning the effects of enhanced SRC cultivation on water budget or groundwater recharge. Particularly sensitive is the beginning of the growing season, i.e. LU. When this estimation is wrong, the accuracy of LAI and Rsc description plays a minor role. Our analyses illustrate that the use of locally measured vegetation parameters, like maximal LAI,
\end{abstract}

and meteorological variables, like air temperature, to estimate LU give better results than literature data or data from remote network stations. However, the direct implementation of locally measured data is not always advisable or possible. Regarding Rsc, the adjustment of local measurements gives the best model evaluation. For local and accurate studies, measurements of model sensitive parameters like LAI, Rsc and LU are valuable information. The derivation of these model parameters based on local measurements shows the best model fit. Additionally, the adjusted seasonal course of LAI and Rsc is less sensitive to different estimates for LU. Different parameterisations, as they are all eligible either from local measurements or scientific literature, can result in modelled ground water recharge to be present or completely absent in certain years under poplar SRC.

\section{Introduction}

In the context of climate change, mitigation and reduction of greenhouse gas (GHG) emissions, bioenergy is one of the possible alternatives for fossil fuels. Among the different bioenergy sources, short rotation coppices (SRC) with mainly poplar and willow trees are promising options in Europe (Djomo et al., 2011). SRC provide woody biomass as well as additional ecosystem services. Seepage water quality 
is enhanced due to lower fertiliser requirements and higher nutrient use efficiency (Aronsson et al., 2000; SchmidtWalter and Lamersdorf, 2012). Compared to conventional annual crops, SRC sequester more carbon and emit less $\mathrm{N}_{2} \mathrm{O}$ (Don et al., 2012), which is one of the most important GHGs. As structural landscape elements in rural areas SRC might also contribute positively to biodiversity (Baum et al., 2012).

However, SRC are not without disadvantages. The most quantitatively assessable disadvantage is the potentially lower groundwater recharge (GWR) being caused by higher evapotranspiration of poplar and willow plantations in comparison to annual crops (Lasch et al., 2010; Schmidt-Walter and Lamersdorf, 2012). An assessment using hydrological models can help to minimise negative and maximise positive ecological effects caused by land use change from arable land to SRC at regional and local scales, e.g. to regional climate and/or to adjacent ecosystems. To adequately quantify the effects of this land use change, the hydrological models must correctly reproduce the hydrological feedback effects of vegetation and land use management. Beside the choice of proper modelling approach, a careful parameterisation of land use and vegetation is needed to obtain reliable simulation results. The aim of the present study is to assess the effect of parameter uncertainties of the land use type poplar SRC on modelling results.

The planting of SRC causes the occurrence of new factors and complex factor interactions influencing site water fluxes. One factor is the perennial vegetation cover with higher leaf area index $\left(\mathrm{LAI} ; \mathrm{m}^{2} \mathrm{~m}^{-2}\right)$ combined with a longer growing season compared to annual crops (Petzold et al., 2010).

LAI directly affects canopy interception due to an almost linear correlation between LAI and canopy storage (Rutter et al., 1971). Outside the growing season LAI, more precisely plant area index (PAI), additionally provides canopy storage by woody biomass - i.e. stems and branches. Furthermore, the transpiration is positively correlated with LAI; i.e. higher LAI causes higher transpiration rates. However, LAI is negatively correlated with soil evaporation as higher LAI results in more shadowing, less solar radiation input and consequently less evaporation below the vegetation cover. Other important parameters controlling the water balance are the stomatal resistance (Rsc), rooting depth and root distribution. The structural and biophysical parameters do not remain constant during the year, but have a seasonal or even annual variability. The largest variations occur during the growing period. Thus, the beginning and length of the growing season should be known for an adequate description of the seasonal dynamic of vegetation parameters.

The smaller the scale of interest, the more time-resolved parameterisation of land use and vegetation is necessary to capture the spatial and temporal variability of effects. There are two possibilities to obtain the required information: the first one is to measure the parameters like LAI or Rsc directly at the investigated site, which is labour consuming and timeconsuming. A second possibility is to use parameters from scientific literature. This information is quite rare for SRC, because this land use scarcely came into focus of investigation as a part of the renewable energy discussion during the last years (Surendran Nair et al., 2012). Typically only one value, rather than the annual course, is given in literature, e.g. the maximum value for LAI, or the minimum value for Rsc, which are related to the maximum transpiration. In such cases the annual course for these parameters has to be estimated for hydrological modelling. Hence, the question on transferability of published results obtained in a certain area and in a specific year to other regions and years has to be solved in each study separately. However, it is well-known that neither literature values nor direct measurements provide the true values of model parameters, but more or less representative approximations, because of spatial and temporal heterogeneity of vegetation stands including SRC.

The overarching aim of our research is the evaluation of land use change effects. However, this study does not focus on land use change effects in any way but rather on the evaluation of a suitable tool. In this study we used the results of our own measurements of LAI, Rsc and the estimation of leaf unfolding date (LU), determining the beginning of growing season, for a poplar SRC to parameterise the hydrological model system WaSim (Wasserhaushalts-Simulations-Model) (Schulla and Jasper, 2013). The aim of the present study is to assess the effect of parameterisation uncertainties of the land use type poplar SRC on modelling results. The hypothesis that the parameterisation of LAI, Rsc and LU based on measurements shows a better model fit than the use of values reported in literature in combination with approximation about the annual course should be proofed. Our specific objectives are (1) to quantify the WaSim response (sensitivity) to variations of following parameters: LAI, Rsc and LU, caused by different measurement methods and modelling approaches; (2) to estimate the most sensitive parameter; and (3) to evaluate quantitatively whether it is advisable to implement locally point-measured values of sensitive parameters directly. We used GWR and plant available water as indicators.

\section{Material and methods}

\subsection{Study site}

The study site Reiffenhausen $\left(51.67^{\circ} \mathrm{N}, \quad 10.65^{\circ} \mathrm{E}\right.$; 325 ma.s.l.) is located south of Göttingen, central Germany. According to the meteorological data provided by the German Weather Service (Deutscher Wetterdienst, DWD), for the station Göttingen (DWD station-ID: 01691), nearest to the study site, the climate is characterised by an average temperature of $9.1^{\circ} \mathrm{C}\left( \pm 0.7^{\circ} \mathrm{C}\right)$ and a mean annual precipitation sum of $635 \mathrm{~mm}( \pm 122 \mathrm{~mm})$ for the period 1971-2010. The site Reiffenhausen was established as part of the interdisciplinary investigations of SRC by the joint integrated project BEST ("Bioenergie-Regionen stärken" 
- Boosting Bioenergy Regions), which ran from 2010 to 2014 and was funded by the German Ministry of Education and Research (BMBF). The aim of BEST was to develop regionally appropriate concepts and innovative solutions for the production of biomass, with focus on SRC, and to evaluate ecological and economic impacts.

The soil in Reiffenhausen is characterised by a sedimentary deposits of Middle and Upper Buntsandstein, like sandstone, siltstone and clay stone. The main soil types present at the field level are Stagnic Cambisol and Haplic Stagnosol with a soil quality (Ackerzahl) of approximately 45 points. The maximum available points are 100 for very good agriculture fields (Blume et al., 2010). The soil texture is dominated by loamy sand or silty clay.

The plantation Reiffenhausen was established at a former arable field in March 2011 with the poplar clone Populus nigra x Populus maximowiczii, hereafter Max1. The poplar SRC were planted with $0.2 \mathrm{~m}$ long cuttings on 0.4 ha in a double row system with alternating inter-row distances of 0.75 and $1.50 \mathrm{~m}$, and a spacing of $1.0 \mathrm{~m}$ within the rows, yielding an overall planting density of 8800 cuttings per hectare. A detailed site description, including soil chemistry and biomass information is given by Hartmann et al. (2014). In 2011 the weather conditions at Reiffenhausen were unfavourably dry for the initial growth after planting. During the first months in 2011, from February to May, the precipitation sum was unusually low: only $42 \%$ of the long-term (1971-2010) precipitation (78 of $188 \mathrm{~mm}$ for the long-term mean value of the same period of the year). This led to dry soil conditions, especially in the upper soil, and resulting in a survival rate of only $63 \%$ for the mono-stem cycle of the poplar SRC. In 2013, when the most measurements and investigations took place the poplar SRC reached a height of 5$6 \mathrm{~m}$, indicating that the unfavourable initial conditions were somewhat improved. All parameters influencing the hydrology in the model are of the order of a fully developed SRC, although it is in mono-stem cycle. The development of the rooting system was eventually enforced by the dry conditions during the initial phase (Broeckx et al., 2013). Rooting depth was more than $1 \mathrm{~m}$ in the second year after planting, exploiting the main part of soil layer above the bedrock (Kalberlah, 2013). The LAI reached 5 in 2012 and 6-7 in 2013, which is typical for a fully grown poplar SRC (Schmidt-Walter et al., 2014).

Observations for LU are also used from the site Großfahner, which is also part of the BEST-research project. Großfahner is located near Erfurt, Thuringia, Germany, and was also established in 2011 with the poplar clone Max1 (Hartmann et al., 2014).

\subsection{Measurements}

\subsubsection{Meteorological and local soil measurements}

In Reiffenhausen, the micrometeorological measurements were carried out in the centre of the SRC stand; the instruments were installed above the vegetation on a $10 \mathrm{~m}$ mast. The air temperature and humidity were measured using Hmp45C (Campbell Sci.; Loughborough, UK); wind speed and wind direction (wind sensor compact and wind direction sensor compact, both ThiesClima; Göttingen, Germany), atmospheric pressure (pressure sensor, Theodor Friedrichs\& Co.; Schenefeld, Germany) and solar radiation (CMP3, Kipp\&Zonen, Delft, the Netherlands) were measured continuously with $1 \mathrm{~Hz}$ frequency and averaged over $15 \mathrm{~min}$. 5 min precipitation sums were obtained using an ombrometer (precipitation transmitter, ThiesClima; Göttingen, Germany). The values were averaged and stored by a CR1000 data logger (Campbell Sci.; Loughborough, UK). In addition to the meteorological measurements in the centre of the poplar SRC, a reference station was similarly equipped and installed approximately $500 \mathrm{~m}$ to the north from the stand in the open place (short-grass meadow) to measure the climate variables unaffected by the poplar SRC.

The soil moisture was measured continuously every 15 min using tensiometers and soil water content probes at 20, 60 and $120 \mathrm{~cm}$ depth, by six (tensiometers) and three (probes) sensors at every depth. Tensiometers were constructed in the Department of Soil Science for the study using the PCFA6D pressure sensor (Honeywell; Morristown, NJ, USA) and a P-80 ceramic (CeramTec AG; Marktredwitz, Germany). Volumetric soil water content and soil temperature were measured using SM-300 probes (Delta-T Devices Ltd; Cambridge, UK). Additionally, descriptions of soil horizons and soil texture were assessed using a soil pit near the SRC.

In addition to the data of Reiffenhausen, meteorological and phenological data are used from the Tharandter Wald (Tharandt Forest) region located in the federal state Saxony (Germany), $15 \mathrm{~km}$ south-west of city of Dresden. As climate characteristics of this region are comparable with Reiffenhausen, a proper set of comparison data are provided. Detailed information about measurement programs of Tharandter Wald can be found, i.a. in Bernhofer (2002) and Spank et al. (2013). In the frame of this study, phenological observation data from the International Phenological Garden (IPG) Tharandt-Hartha and meteorological measurement data (air temperature, air humidity and precipitation) from climate stations Grillenburg and Wildacker have special importance. Grillenburg and Wildacker are the nearest meteorological long-term measurements sites from IPG and are situated about $3 \mathrm{~km}$ away. Both stations provide meteorological and climatological information since 1958. Grillenburg represents a standard meteorological station fulfilling all guidelines and standards of the World Meteorologi- 
cal Organisation (WMO) for large-scale representativeness of climatological observations. However, measurements on this site sometimes do not describe local climatic characteristic of the region, particularly related to the daily minimum and maximum of air temperature. In contrary, the climate station Wildacker, not fulfilling WMO standards of fetch and horizon heightening, better represents the local climatic situation.

\subsubsection{Leaf area index}

For the present study we use the definition of leaf area index by Watson (1947) cited in Breda (2003) as the total one-sided area of leaf tissue per unit ground surface area with the dimension of $\mathrm{m}^{2} \mathrm{~m}^{-2}$ (or dimensionless). There are numerous ground-based as well as remote sensing-based techniques to estimate LAI. An extensive overview of ground-based methods is given by Breda (2003). Direct methods, such as allometric, litter collection and harvesting, are based on statistically significant sampling of phytoelements and phytoelement dimensions. Among these method, only the harvesting can provide the information on the seasonal dynamic of LAI for the whole season or year. The obvious disadvantages of harvesting as a destructive method, however, are that it is very time-consuming and labour consuming, the canopy is irreversibly damaged and further statistically representative LAI measurements for seasonal dynamics are affected.

Indirect ground-based methods are non-destructive and based on the inversion of the Beer-Lambert law, i.e. on measurements of the extinction of short-wave solar radiation by the canopy. The extinction is related to the vegetation structure parameters including LAI (Eq. 1).

$\mathrm{LAI}=\frac{\ln \left(I / I_{0}\right)}{k} \quad$ with $\quad k=\frac{G(\Theta, \alpha)}{\cos \Theta}$

where LAI is the leaf area index for the vegetation layer, $I_{0}$ is the radiation intensity incident to the vegetation layer, $I$ radiation intensity at the lower bound of vegetation layer and $k$ is the extinction coefficient (Breda, 2003). The function $G$ is the projection of unit foliage area on the plane normal to the direction $\Theta, \Theta$ zenith angle and $\alpha$ the leaf angle distribution. It should be also noted that indirect methods do not estimate LAI rather PAI as the light attenuation is caused not only by leaves but also by branches and tree stems as well. To derive LAI, either the share of woody material is subtracted from PAI, or it is assumed that the attenuation is caused for the most part by leaves (especially for dense canopies). The underlying assumptions, e.g. on stand homogeneity and small black opaque phytoelements that have to be considered to ensure the applicability of indirect methods, as well as advantages and disadvantages of various methods, are presented, e.g. in the LAI-2000 Manual (LI-COR INC, 1992), in Breda (2003) and (Jonckheere et al., 2004).

For the present study the data of one direct and two indirect methods for the estimation of LAI of the poplar SRC in
Reiffenhausen were used. For the indirect method we used two different types of instruments. First, two LI-191 SA Line Quantum Sensors (LI-COR Inc., USA) were used to measure incident $\left(I_{0, \mathrm{PAR}}\right)$ and within-stand photosynthetic active radiation ( $I_{\mathrm{PAR}}$ ) to calculate the LAI using Eq. (1). The $k=0.5$ for mixed broadleaved species was accepted in our study (Breda, 2003). Second, two plant canopy analysers LAI-2000 (LI-COR Inc., USA) were implemented in two-sensor mode (LI-COR INC, 1992) to obtain LAI and $k$. Measurements were performed weekly whenever possible from May to November 2013 under homogenous illumination, i.e. at days with overcast conditions or during morning or evening hours. Sensor pairs were cross-validated at the beginning of each measurement day.

In the homogeneous poplar SRC 10 evenly distributed plots were selected. To account for the double row planting of the $\mathrm{SRC}, 3 \mathrm{~m} \times 3 \mathrm{~m}$ square grids with $1 \mathrm{~m}$ distance between grid points were marked at every plot so that 16 grid points per plot were obtained for measurements. At each grid point two measurements were performed with instruments oriented along and perpendicularly to SRC rows. Thus, 32 measurements were performed at each of 10 plots during every measurement day. The LAI-2000 was used in two-instrument mode with $25 \%$ view restriction caps to eliminate the influence of operator. The measurements with line quantum sensors LI-191SA were also carried out in two-instrument mode; the measurement design was identical to LAI-2000.

To obtain the reference values for leaf area, the direct destructive sampling, i.e. harvesting, was carried out. All phytoelements within the square column of $1 \mathrm{~m}^{2}$ surface area were collected and measured with leaf area meter (LI-3100; LI-COR Inc., USA). The sampling was carried out on $26 \mathrm{Au}-$ gust 2013 at three plots within the investigated stand.

\subsubsection{Stomatal resistance}

The dominant factor controlling both the water loss from plant leaves and the uptake of $\mathrm{CO}_{2}$ for photosynthesis is the resistance of stomata, regulated by the plant in response to environmental conditions. Stomatal resistance, or the reciprocal stomatal conductance, is an important parameter in hydrological modelling, as it controls the transpiration rate for different vegetation types. The version of WaSim applied in the present study uses the Penman-Monteith approach for calculating evapotranspiration and requires a parameter of minimal surface resistance for a state when plants are fully supplied with water (Schulla, 1997; Schulla and Jasper, 2013). The real transpiration modelled is further influenced by meteorological boundary conditions and the available soil water.

For the Rsc measurements in poplar SRC, we used the SC-1 leaf porometer (Decagon Devices Inc.; Pullman, WA, USA). The measurements took place in Reiffenhausen in 2013 and were carried out weekly or fortnightly from May to September only under favourable weather conditions promis- 
ing minimal resistances: preferable sunny, but at least without rain and with dry leaves. The same 10 plots in the poplar SRC as for the LAI measurements were used, where three sun leaves were marked to be measured at different times. All 10 locations were measured during $1 \mathrm{~h}$ to minimise the effects of changing weather conditions. Measurements were started in the morning and when leaves are dry and continued till afternoon, or as long as weather conditions were appropriate.

\subsubsection{Phenology - start of growing season}

The phenological phases of plants, e.g. leaf unfolding, leaf colouring and the falling of leaves, are controlled by environmental conditions and internal genetic characteristics of plants. Thus, the site and species-specific phenological state is a result of complex interference between length of day, meteorological drivers (mainly temperature and radiation), soil properties, plant provenance, age and height (Menzel, 2000).

Within WaSim a modified approach for estimating LU according to Cannell and Smith (1983) is implemented and used here. A detailed description of this model as presented in Eqs. (2-5), as well as parameterisation examples (Table 1) is given by Menzel (1997).

The model has four parameters: $T_{0}, T_{1}, a$ and $b$ which are the threshold temperatures for chilling units and for forcing units and two tree-specific regression parameters, respectively. The starting day for leaves unfolding is calculated according to Eqs. (2), (3), (4) and (5).

$T_{\mathrm{S}}=\sum_{i=0}^{n}\left\{\begin{array}{ll}T\left(t_{1}+i \Delta t\right)-T_{1} & T\left(t_{1}+i \Delta t\right) \geq T_{1} \\ 0 & T\left(t_{1}+i \Delta t\right)<T_{1}\end{array}\right.$,

where $T_{\mathrm{S}}$ is the temperature sum, $T$ the daily mean temperature for a day $t_{1}+i \Delta t, t_{1}$ set as 1 February in present study and time step, $\Delta t$, as 1 day. The daily mean temperature is calculated according to Eq. (3).

$T=\frac{T_{\min }+T_{\max }}{2}$,

where $T_{\min }$ is the daily minimum temperature and $T_{\max }$ the daily maximum temperature. The LU occurs when $T_{S}$ reaches the critical value $T_{\mathrm{S} \text {, crit }}$ (Eqs. 4 and 5).

$T_{\mathrm{S}, \mathrm{crit}}=a+b \ln \left(\mathrm{CD}_{n}\right)$

with

$\mathrm{CD}_{n}=\sum_{i=0}^{n} \begin{cases}1 & T\left(t_{0}+i \Delta t\right) \leq T_{0} \\ 0 & T\left(t_{0}+i \Delta t\right)>T_{0}\end{cases}$

$\mathrm{CD}$ is the number of chilling days, i.e. when $T<T_{0}$, between days $t_{0}$ and $t_{1}$. The date $t_{0}$ was set as 1 November in present study. Values for $T_{0}, T_{1}, a$ and $b$ for Populus tremula (IPG235) are given by Menzel (1997; Table 1)
Table 1. Parameters of the modified approach for estimating leaf unfolding (LU) according to Cannell and Smith (1983), which is used in WaSim. Estimated day of years (DOY) of LU for Reiffenhausen (2012 and 2013) are used to calibrate the Max1 parameters $T_{0}, T_{1}, a$ and $b$, i.e. threshold temperature for chilling units and forcing units and regression parameters of two poplars, i.e. Max1 and IPG235 (Populus tremula), respectively. Additionally, the parameter set for IPG235 according to (Menzel, 1997, Appendix A7) is shown.

\begin{tabular}{lrr}
\hline Parameter & $\begin{array}{r}\text { Max1 } \\
\text { (present study) }\end{array}$ & $\begin{array}{r}\text { IPG235 } \\
\text { (Menzel, 1997) }\end{array}$ \\
\hline$T_{0}\left[{ }^{\circ} \mathrm{C}\right]$ & 10 & 8 \\
$T_{1}\left[{ }^{\circ} \mathrm{C}\right]$ & 2 & 5 \\
$a$ & 2200 & 1693.4161 \\
$b$ & -403 & -301.9361 \\
\hline
\end{tabular}

Using these numbers as initial values we fitted the parameters $T_{0}, T_{1}, a$ and $b$ to observed LU for the poplar clone Max 1 in Reiffenhausen for the years 2012 and 2013 using a least squares method. Finally we evaluated the obtained model parameters against the independent observations in Reiffenhausen (for 2014), and observation in Großfahner for the years 2012 and 2013 (Lorenz and Müller, 2013) and 2014 (K. Lorenz, personal communication, 2014). The observed LU in Reiffenhausen and Großfahner is comparable to the recommendations according to Volkert and Schnelle (1966). Because the estimation of LU, as used in this study is based on meteorological measures, the parameterisation should hold true for the same poplar clone in the same age, if other environmental factors are of minor importance. The results will confirm this.

For a long-term comparison, the data from the international phenological observation networks (IPG) are used (Chmielewski et al., 2013), namely LU of Populus tremula (IPG235) at the IPG station Tharandt-Hartha. For poplar clone Max 1 we could not find parameter sets in the literature; therefore, for comparison we used the IPG235 parameters of Menzel (1997) for Populus tremula, which has been more extensively investigated. The IPG data are used for long-term comparison, because there were no long-term investigations of LU available on the research plots of the BEST project or nearby. IPG235 is the acronym of the parameterisation for Populus tremula used by (Menzel, 1997). We decided to retain this acronym to make it comparable to published results, and also because it is an acronym used in the data provided by the phenological garden network. The phenological phase of leaf unfolding is defined as the stage UL, according to the IPG web page (International Phenological Gardens of Europe, 2014) and is obtained by daily observations of plant's development state. The IPG station Tharandt-Hartha is located at the eastern border of the Tharandter Wald. It is the nearest IPG station to the Reiffenhausen site, and comparable in climate and altitude. 


\subsection{Modelling approach}

For simulation, the deterministic spatially distributed hydrological catchment model system WaSim (version 9.05.04) was used. Complete and comprehensive descriptions of this model and its internal structure can be found inter alia in (Schulla, 1997; Schulla and Jasper, 2013). The set up of physically based parameters, such as LAI and Rsc as well as phenological state (date of leaf unfolding - LU here), are predicated on direct measurements and observations. Thus, physical nexus between model image and reality is reproduced as best as possible. The SRC described with these measurements and observations represents a poplar SRC in the third growing season of its mono-stem cycle, which can be seen as a hydrological fully developed canopy, concerning LAI, Rsc and root development. The simulated local soil water contents were compared and evaluated to the measurements.

Different model simulations are done to show the suitability of the direct use of specific plant physiological measurements, as well as the effects of an approximated parameter description in the model, i.e. the annual course and the quantity of LAI, Rsc and phenology.

All these model approaches were done on a plot model domain, which are $3 \times 3$ raster cells based on a digital elevation model with a spatial resolution of $12.5 \mathrm{~m}$ (LGLN Landesbetrieb Landesvermessung und Geobasisinformation, 2013), provided by the project partner NW-FVA ${ }^{1}$. All topographic information needed by the model is derived by the model itself. The research site, providing the measured soil water contents for model calibration is located in the centre of the domain. A retention curve required in hydrological modelling for the description of soil physical properties was taken from Van Genuchten (1980). The Van Genuchten retention parameters from Blume et al. (2010) were accepted based on a characterisation of soil texture and soil horizons in Reiffenhausen.

The meteorological forcing data were taken from our own measurements for the period 2011-2013, whereas the first 2 years were used for the model spin-up. Analyses and the comparison to measured local soil water contents were done just for the year 2013. To show the effects of different parameterisations under various climate conditions, the simulations were performed for the period from 1969 to 2013 using the forcing meteorological data from the DWD station Göttingen. The period was chosen as the longest period without missing values. The parameterisation of land use is kept constant for the whole period. A WaSim control file including all information about parameterisation and model set up is provided as supplementary material.

\footnotetext{
${ }^{1}$ Nordwestdeutsche Forstliche Versuchsanstalt (NW-FVA), North-west German Forest Research Station
}

\subsection{Data analysis}

All measured and applied meteorological, soil physical and eco-physiological parameters have been checked for plausibility and measurement errors.

The data have been numerically analysed and graphically presented with the free software package GNU Octave, version 3.6.2 (Octave community, 2012). Parts of the statistical analysis were performed using the hydroGOF package (Mauricio Zambrano-Bigiarini, 2014) within the R software environment (R-Studio under Windows, version 0.98.501) for statistical computing and graphics (R Development Core Team, 2011).

The evaluation of model performance was done according to the objective criteria of Moriasi et al. (2007). Important quality criterions of simulation runs are the Nash-Sutcliffe model efficiency criterion (NSC), the percent bias (PBIAS), and the ratio of the root mean square error to the standard deviation of measured data (RSR).

\section{Results}

\subsection{Measurements}

\subsubsection{Leaf area index}

Figure 1 shows the annual course of LAI as derived from two different indirect optical methods and one direct destructive method. LU started shortly before the first measurement on 1 May 2013. Until 1 August there was almost a linear increase of LAI up to 7.3 and 5.5 for the LI191SA and the LAI2000 measurements, respectively. After that LAI started to decrease, with a more rapid decline toward the end of $\mathrm{Au}-$ gust 2013. Leaf fall was almost finished at 25 October.

Differences between devices, i.e. LI191SA vs. LAI2000, are large. The LAI values obtained with the LI191SA are systematically higher $\left(\approx 2 \mathrm{~m}^{2} \mathrm{~m}^{-2}\right)$. The values obtained by direct destructive sampling at 26 August are rather on the level of the LAI2000 estimates.

\subsubsection{Stomatal resistance}

Figure 2 shows the stomatal resistance (Rsc) as measured on well-illuminated leaves in 2013. The values ranged from 100 to $300 \mathrm{~s} \mathrm{~m}^{-1}$ until August 2013. On 18 June Rsc was higher with larger standard deviations as the previous measurement on 14 June. Soil water supply was sufficient on both days. The 2 days significantly differ in temperature, although June 14 was relatively colder with a daily maximum temperature of approximately $17^{\circ} \mathrm{C}$, while 18 June was quite hot, reaching a maximum temperature of $33^{\circ} \mathrm{C}$. This shows the effect of local environmental conditions to measurements, possibly influencing derived model parameters. From August on, both mean Rsc and standard deviation steadily increased. This period was characterised by decreasing soil water availability 


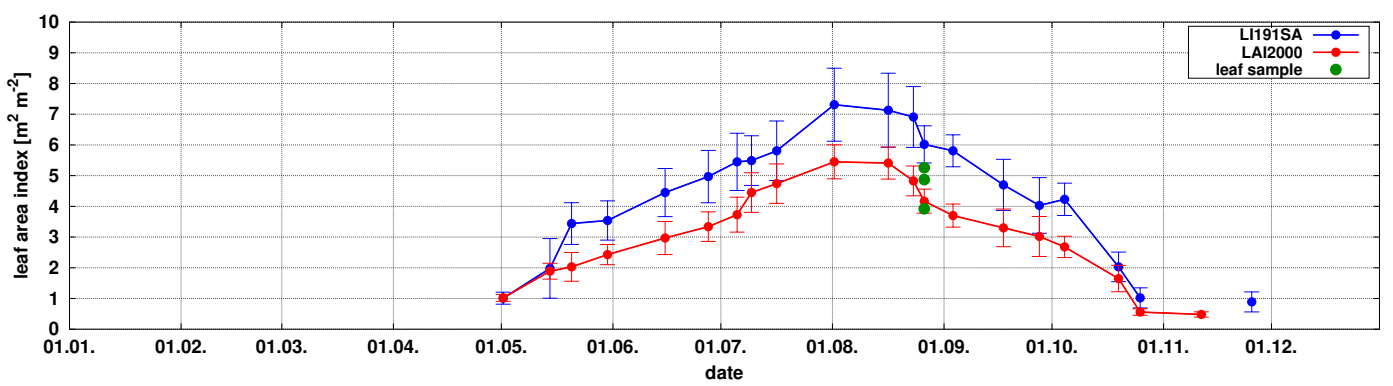

Figure 1. Means and standard deviations of leaf area index of the poplar SRC Reiffenhausen in 2013. Measurements of two optical devices: LI191SA calculated with constant extinction coefficient $k=0.5$ and LAI2000 are shown. LAI values obtained by destructive harvesting at 26 August on three plots are shown as green dots.
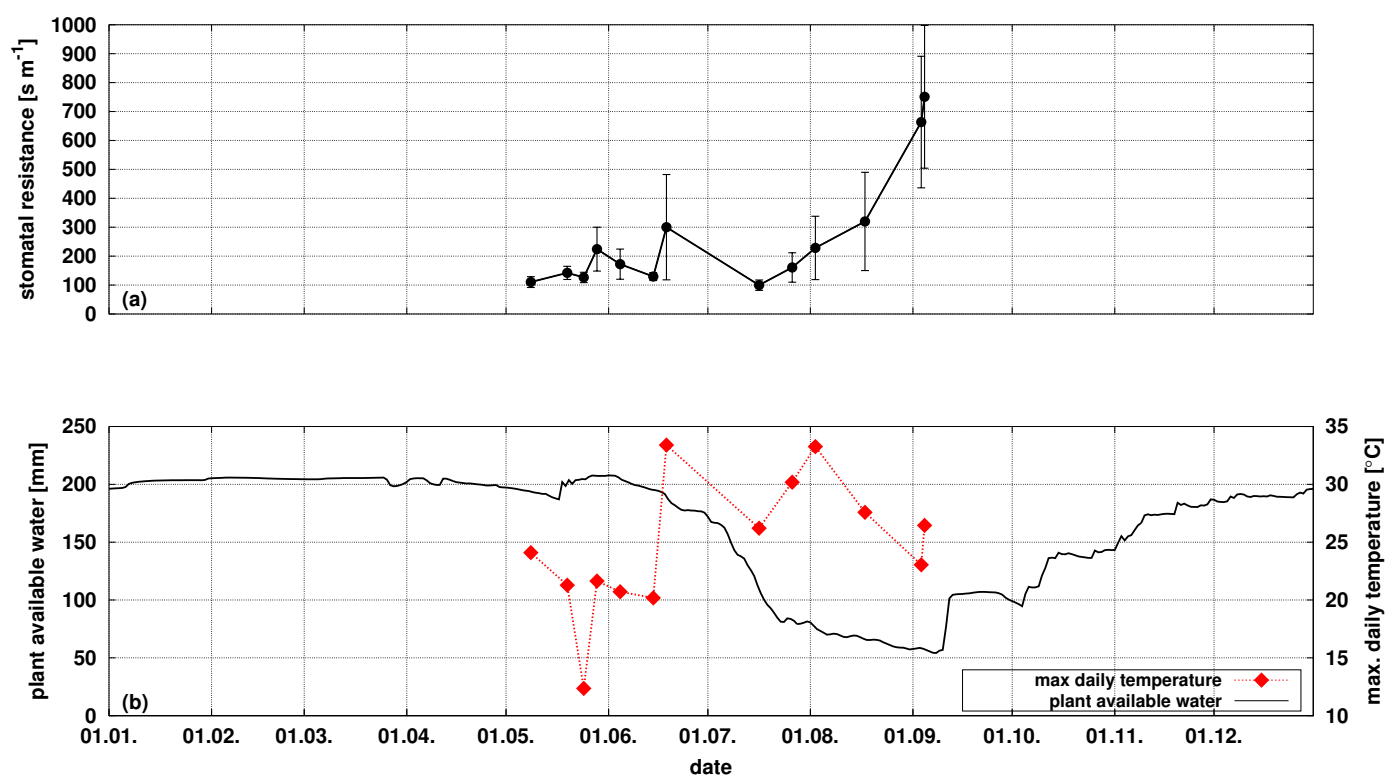

Figure 2. (a) Means and standard deviations of stomatal resistance of sun leaves derived from 10 to 11 repetitions every day at 10 measurement plots and (b) the plant available water, calculated from soil water content measurements until $1 \mathrm{~m}$ soil depth and daily maximum temperature at the poplar SRC Reiffenhausen in 2013. High temperatures affecting stomatal resistance (18 June); starting from August drought stress occurred, increasing the stomatal resistances.

leading to severe drought stress conditions. Due to higher Rsc the trees counteracted the drought stress to avoid water loss and xylem damage, e.g. embolism of xylem vessels. The increase of standard deviation is an expression of stand heterogeneity, single trees still have access to water, and others may already be limited or stressed. In September 2013 we stopped measurements because leaves were visibly affected by the drought stress event. The correlation of plant available soil water and plant regulation via stomata seems to be consistent, increasing confidence in the distinct measurements. The minimum observed stomatal resistance is $80 \mathrm{~s} \mathrm{~m}^{-1}$.

\subsubsection{Phenology - start of growing season}

We used in situ phenological observations of the 2 years 2012 and 2013 in Reiffenhausen to calibrate the modified approach for estimating LU according to Cannell and Smith (1983), which is used in WaSim. In 2012 LU for Max1 in Reiffenhausen started at day of year (DOY) 88, i.e. 28 March 2012 (Table 2). In 2013 LU was delayed by approximately 4 weeks due to low temperatures in spring and started at DOY 115 (25 April 2013). Our calibration resulted in values of 10 and $2{ }^{\circ} \mathrm{C}$ for $T_{0}$ and $T_{1}$. The regression parameters $a$ and $b$ are 2200 and -403 , respectively (Table 1). Estimates of LU using these values for $T_{0}, T_{1}, a$ and $b$ show deviations from the observed dates of +3 and -3 days for Reiffenhausen in 2012 and 2013, respectively (Table 2). Then the phenological model results with the obtained parameter set and local temperatures were compared to phenological observations in Reiffenhausen in 2014 and in Großfahner in 2012 and 2013. Observed LU in Großfahner were almost equal to that in Reiffenhausen, also showing the delay of about 4 weeks in 
Table 2. Observed and estimated day of years (DOY) of leaf unfolding (LU) for Reiffenhausen and Großfahner. The Max 1 parameters are calibrated at the observations in Reiffenhausen using local temperatures (2012 and 2013) and evaluated with Reiffenhausen (2014) and Großfahner (2012-2014). Additionally the DOY of LU is compared to estimates using the IPG235 parameter set as well as the temperatures of the nearest DWD climate station (Göttingen for Reiffenhausen, distance approx. $17 \mathrm{~km}$; Dachwig for Großfahner, distance approx. $3.5 \mathrm{~km}$ ) are presented.

\begin{tabular}{lrrrrr}
\hline & Observed & Max1 & Max1 & IPG235 & IPG235 \\
\hline Temperature data & & local & $\begin{array}{r}\text { nearest } \\
\text { DWD }\end{array}$ & local & $\begin{array}{r}\text { nearest } \\
\text { DWD }\end{array}$ \\
\hline Reiffenhausen DOY 2012 & 88 & 91 & 89 & 119 & 121 \\
Reiffenhausen DOY 2013 & 115 & 112 & 112 & 125 & 126 \\
Reiffenhausen DOY 2014 & 83 & 82 & 85 & 111 & 113 \\
Großfahner DOY 2012 & 88 & 89 & 88 & 111 & 112 \\
Großfahner DOY 2013 & 114 & 113 & 112 & 121 & 121 \\
Großfahner DOY 2014 & 89 & - & 86 & - & 103 \\
\hline
\end{tabular}

2013 compared to 2012. The phenological model using the Max 1 parameters results in differences of -1 day for Reiffenhausen in 2014 and of +1 and -1 days for Großfahner in 2012 and 2013 compared to observations. Table 2 also shows the application of the IPG235 parameter set provided by Menzel (1997) for Populus tremula. Parameters of $a$ and $b$ for IPG235 are both smaller in magnitude and threshold temperatures for chilling and forcing units, $T_{0}$ and $T_{1}$ show smaller differences. Due to this widespread between $T_{0}$ and $T_{1}$, the Max 1 model is able to describe extreme values and therefore a higher variability of LU, which was observed in 2012 and 2013. The model estimations of LU with Max1 and with the IPG235 parameters differ considerably. The IPG235 set produces systematically later dates. Differences in observations are +31 (2012), +10 (2013) and +28 (2014) days for Reiffenhausen and +23 (2012) and +7 (2103) days for Großfahner using the local temperatures (Table 2, column: local).

To assess the effects of non-local micrometeorological data sources, the model was driven by temperature measurements from the nearest DWD stations, namely, Göttingen for Reiffenhausen and Dachwig for Großfahner. As expected, the use of DWD data instead of the local measurements produces mostly larger estimation errors for both the Max1 and the IPG235 parameter set (Table 2, column: nearest DWD).

We used the varying parameter sets, i.e. our Max 1 model and the IPG235 parameter set (Table 1) to analyse the effect for hydrological modelling for the year 2013, where soil hydrological measurements are available to evaluate the hydrological model results.

To analyse the species dependence of LU estimations, the model with Max 1 and IPG235 parameters was also driven by temperature measurements during 2012-2014 at the phenological station Tharandt. Figure $3 a-d$ illustrate that the parameter sets better fit with the observations at species for which they were calibrated: Max1 parameters to Reiffenhausen and the IPG235 parameters to Tharandt observations, which were part of its calibration data set. The differences between estimated and observed DOY of LU are smaller when local temperature measurements are used (Fig. 3a vs. b and Fig. 3c vs. d).

Figure 3e-f show the long-term courses of estimated DOY of LU for Reiffenhausen and Tharandt using the temperatures of the nearest DWD stations (Göttingen and Wildacker, respectively). The model with IPG235 is systematically later and shows less variability than with Max1 parameters. For Reiffenhausen no long-term phenological observations are available. However, the average DOY of LU in Reiffenhausen is DOY $97 \pm 9$ days using Max 1 and DOY $124 \pm 5$ days for IPG235. The long-term phenological observations in Tharandt fit well with the IPG235 estimates, but showing less variability than observed. The average DOY of LU in Tharandt as observed is DOY $123 \pm 10$ days, estimated using Max1 DOY $101 \pm 9$ days and with IPG235 DOY $124 \pm 7$ days. In general, the estimations fit best to observations when the corresponding parameters are used, i.e. Max1 for Reiffenhausen and IPG235 for Tharandt. But variability is underestimated by IPG235 compared to observations.

\subsection{Hydrological model simulations}

Several model simulations were performed with different parameterisations of LAI, Rsc and LU. Table 3 summarises the eight performed model simulations and introduces their abbreviations. The detailed descriptions of model simulations are given in the text.

First the measured values of LAI, Rsc and LU are implemented for hydrological modelling (LAI2000 Rsc80 and LI191SA Rsc80). Starting from here we changed the parameter sets: (i) to improve the model fit, (ii) to adjust the suitability of applied parameterisations and (iii) to show the effects of different parameterisations on hydrological model results. 

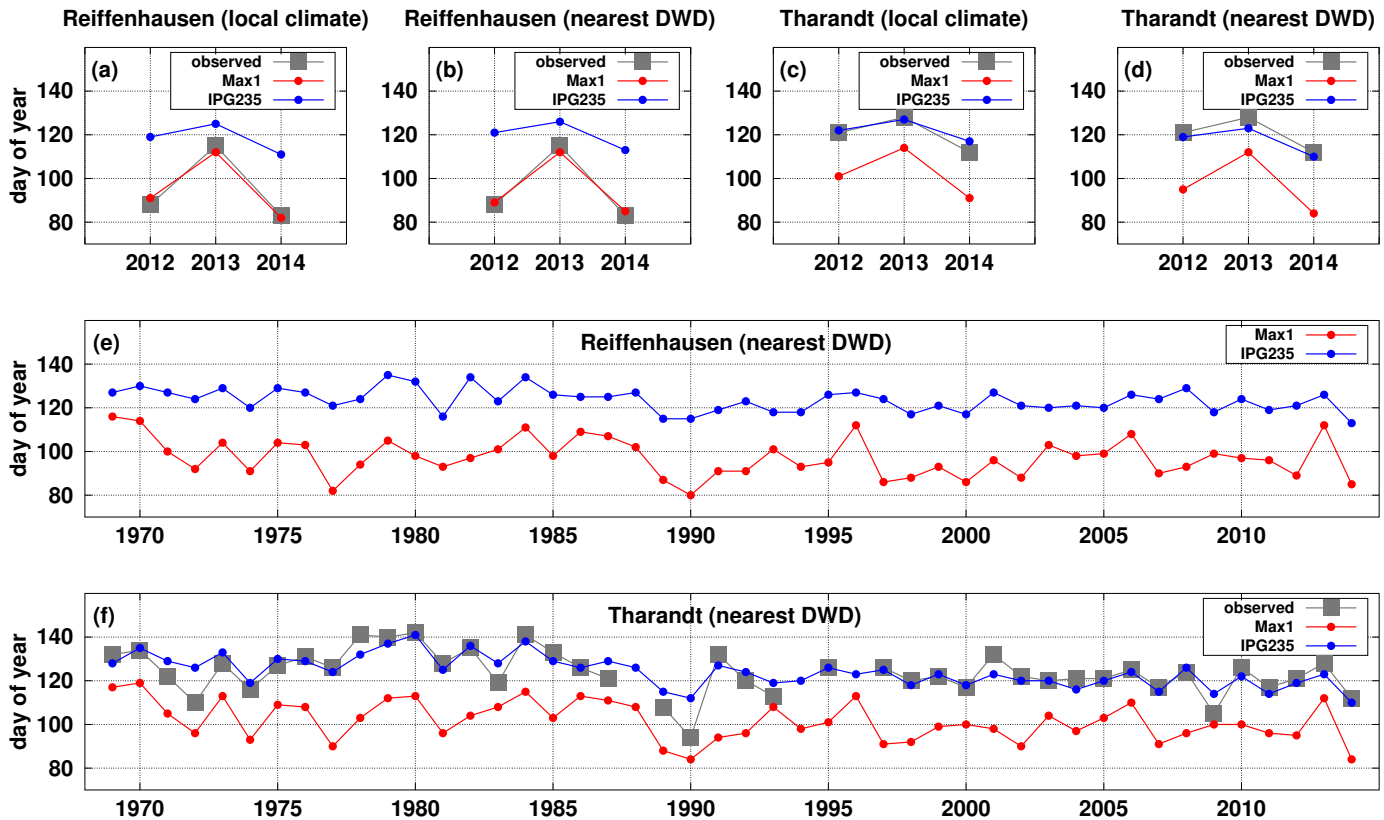

Figure 3. Estimated day of year (DOY) of leaf unfolding (LU) using the Max1 and IPG235 parameters for the site Reiffenhausen with local temperature measurements (a) and temperatures from the nearest DWD station Göttingen (b) for the years 2012 to 2014; same for Tharandt, local temperatures (c) and nearest climate station Wildacker (d); with observations. The lower subplots show long-term estimates for DOY of LU using the DWD temperatures for Reiffenhausen (e) and for Tharandt (f), where also long-term observations are available.

Table 3. Description of the eight performed model simulations. All model parameters are constant, except leaf area index (LAI), stomatal resistance (Rsc) and the date of leaf unfolding (LU) for the two parameter sets Max1 and IPG235.

\begin{tabular}{|c|c|c|c|}
\hline Version & LAI & Rsc & LU \\
\hline LAI2000 Rsc80 & $\begin{array}{l}\text { LAI-2000 } \\
\text { measurements }\end{array}$ & $\begin{array}{l}\operatorname{minimum} 80 \mathrm{~s} \mathrm{~m}^{-1} \\
(\mathrm{LAI}>1)\end{array}$ & $\begin{array}{l}\text { defined by } \\
\text { measured LAI }\end{array}$ \\
\hline LAI2000 Rsc40 & $\begin{array}{l}\text { LAI-2000 } \\
\text { measurements }\end{array}$ & $\begin{array}{l}\operatorname{minimum} 40 \mathrm{~s} \mathrm{~m}^{-1} \\
(\mathrm{LAI}>1)\end{array}$ & $\begin{array}{l}\text { defined by } \\
\text { measured LAI }\end{array}$ \\
\hline LI191SA Rsc80 & $\begin{array}{l}\text { LI-191 SA } \\
\text { measurements }\end{array}$ & $\begin{array}{l}\operatorname{minimum} 80 \mathrm{~s} \mathrm{~m}^{-1} \\
(\mathrm{LAI}>1)\end{array}$ & $\begin{array}{l}\text { defined by } \\
\text { measured LAI }\end{array}$ \\
\hline LI191SA Rsc40 & $\begin{array}{l}\text { LI-191 SA } \\
\text { measurements }\end{array}$ & $\begin{array}{l}\operatorname{minimum} \\
(\mathrm{LAI}>1)\end{array}$ & $\begin{array}{l}\text { defined by } \\
\text { measured LAI }\end{array}$ \\
\hline LAIstep Rsc40 Max1 & $\begin{array}{l}\text { step function } \\
\text { (6 in growing season; else } 1)\end{array}$ & $\begin{array}{l}\operatorname{minimum} 40 \mathrm{~s} \mathrm{~m}^{-1} \\
(\mathrm{LAI}>1)\end{array}$ & Max 1 model \\
\hline LAIstep Rsc40 IPG235 & $\begin{array}{l}\text { step function } \\
\text { ( } 6 \text { in growing season; else } 1)\end{array}$ & $\begin{array}{l}\operatorname{minimum} \\
(\mathrm{LAI}>1)\end{array}$ & IPG235 model \\
\hline $\begin{array}{l}\text { LAIadjusted } \\
\text { Rsc40adjusted Max1 }\end{array}$ & $\begin{array}{l}\text { course calibrated to improve } \\
\text { model fit }(\max .=6)\end{array}$ & $\begin{array}{l}\operatorname{minimum} 40 \mathrm{~s} \mathrm{~m}^{-1} \\
(\mathrm{LAI}>1)\end{array}$ & Max1 model \\
\hline $\begin{array}{l}\text { LAIadjusted } \\
\text { Rsc40adjusted IPG235 }\end{array}$ & $\begin{array}{l}\text { course calibrated to improve } \\
\text { model fit }(\max .=6)\end{array}$ & $\begin{array}{l}\operatorname{minimum} \\
(\mathrm{LAI}>1)\end{array}$ & IPG235 model \\
\hline
\end{tabular}

\subsubsection{Simulation using observed parameters and adaptation of stomatal resistance}

First we used the measured annual courses of LAI for hydrological modelling. Rsc is set to the measured minimum of $80 \mathrm{~s} \mathrm{~m}^{-1}$ when LAI is larger than 1 . LU is not calculated for measured LAI from air temperature using the approach of Cannell and Smith (1983), because this information is already imprinted in LAI measurements and therefore fixed for the year 2013.

Figure 4 shows the applied model parameterisations for LAI and Rsc, as well as the plant available water (PAW), calculated for $1 \mathrm{~m}$ soil depth from measured and modelled soil water contents. 

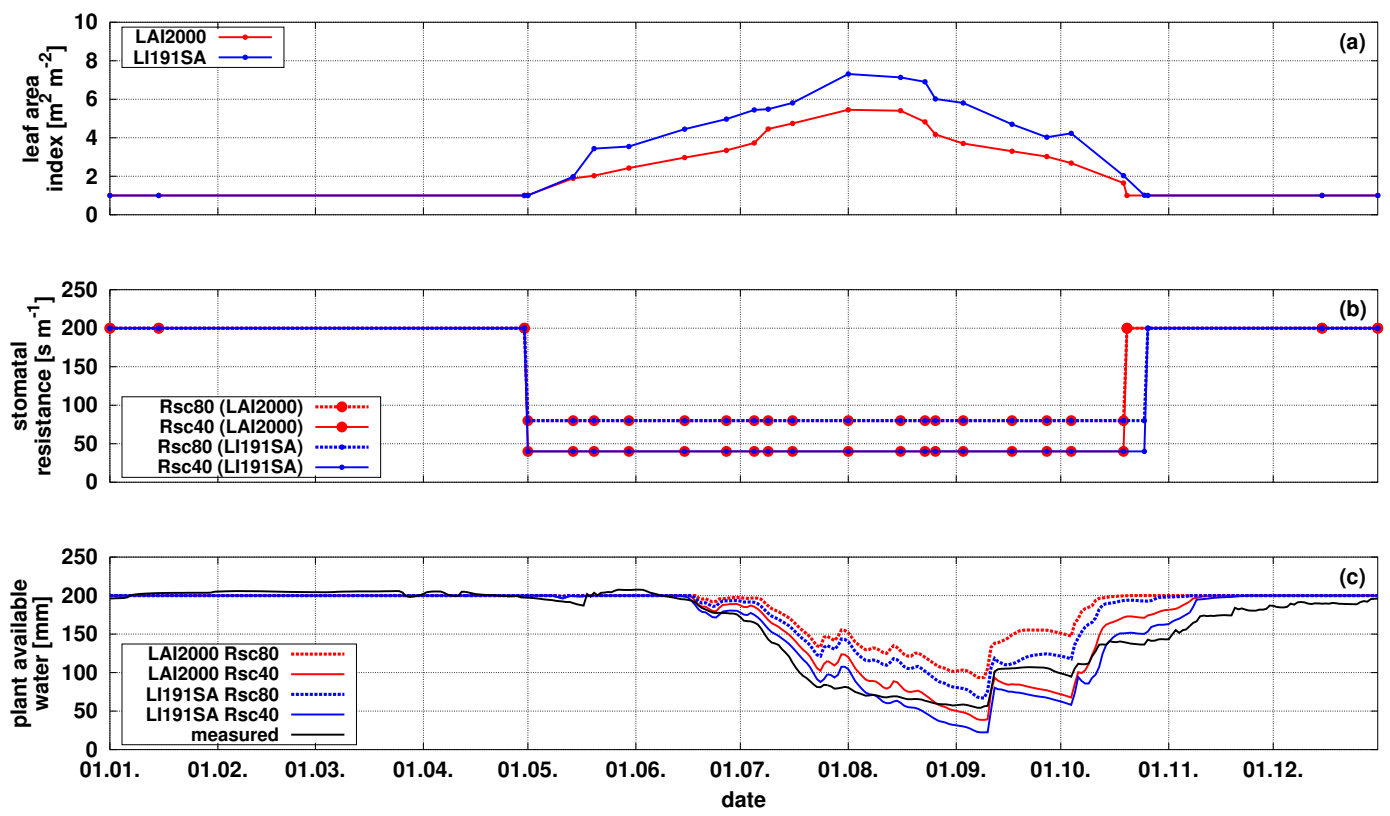

Figure 4. Leaf area index and stomatal resistance as parameterised from measurements. Leaf area index is used as measured, LAI2000 (red) and LI191SA (blue). Stomatal resistance is set to the measured minimum, i.e. $80 \mathrm{~s} \mathrm{~m}^{-1}$ (dashed line) and to $40 \mathrm{~s} \mathrm{~m}^{-1}$ (solid line) as leaf area index is larger than 1. Length of growing season is determined by the leaf area observations. Simulation results using the four combinations of leaf area index and stomatal resistance are shown as plant available soil water, calculated until $1 \mathrm{~m}$ soil depth and compared to values based on soil water content measurements.

For all simulations using the measured value for Rsc (i.e. $80 \mathrm{~s} \mathrm{~m}^{-1}$ ), the modelled soil water contents were higher than measured values, resulting in larger PAW values than observed. This is also reflected by the Nash-Sutcliffe criterion (NSC) calculated from PAW (Table 4). The annual course of PAW is captured quite well by the model, but the drying up in summer is not sufficient, neither for LI191SA, nor for LAI2000 measurements. The NSC is better for the experiments with LAI measured by LI191SA (0.69) than with LAI2000 (0.44) because of the higher LAI values (Table 4).

As the maximum LAI measurements using LAI2000 showed better agreement with direct destructive measurements, we halved the value of Rsc from 80 to $40 \mathrm{~s} \mathrm{~m}^{-1}$ to reach the low PAW values observed. This decision is justified by two reasons: first, it can be assumed that the measured Rsc is always higher than the minimum value needed for parameterisation, because the conditions by measuring Rsc are not satisfying the requirements for the parameter to be used in the model - i.e. optimal conditions for transpiration and no water stress. Another way to get lower PAW values would be to increase the LAI, as can be seen by comparing the results for LI191SA and LAI2000. However, in our experiment LAI has to be increased to unrealistically high values to minimise the differences to observed PAW. Additionally LAI is also affecting other processes in hydrological models, like interception evaporation and soil evaporation. Together the decrease of Rsc is a consistent way to minimise the deviations to observations and to improve the model fit.
The reduction of Rsc, from 80 to $40 \mathrm{~s} \mathrm{~m}^{-1}$, improved the NSC from 0.69 and 0.44 to 0.89 and 0.87 for LI191SA and LAI2000, respectively (Table 4).

\subsubsection{Approximation and adaptation of annual course of leaf area and stomatal resistance}

In many cases when hydrological models should be applied for analyses involving vegetation, there are no locally measured data on LAI and/or Rsc. Often only the literature data for the maximum and minimum values of LAI and Rsc are available. Then the annual course for these parameters has to be derived or approximated for modelling. The simplest approximation is a stepwise function, where the increase from minimum to maximum or decrease from maximum to minimum occurs within one time step. We applied this form to the LAI and Rsc as shown in Fig. 5. Here the maximum of LAI is set to $6 \mathrm{~m}^{2} \mathrm{~m}^{-2}$, which is the observed maximum plus standard deviation of LAI2000 measurements. The minimum of Rsc is set to $40 \mathrm{~s} \mathrm{~m}^{-1}$. For this kind of approximation the start and length of the growing season become important, because the maximum transpiration rate occurs immediately after LU. In Fig. 5 we compare two different parameterisations for dynamical estimating LU, i.e. the Max1 and the IPG235 parameter set (Table 1).

The NSCs for both simulations are 0.89 (Table 4), which is slightly better than for applying the direct LAI measurements. However, PBIAS values are negative for the step- 
Table 4. Statistical parameters for model evaluation in terms of the accuracy of simulated data compared to measured values. Nash-Sutcliffe efficiency criterion (NSC), percent bias (PBIAS), and ratio of the root mean square error to the standard deviation of measured data (RSR) are calculated from plant available soil water till $1 \mathrm{~m}$ soil depth as derived from model simulations and soil water content measurements for the period from April to December 2013, to cover the period of most variability.

\begin{tabular}{lrrr}
\hline & NSC & RSR & PBIAS [\%] \\
\hline $\begin{array}{l}\text { Recommended as satisfactory } \\
\text { by (Moriasi et al., 2007) }\end{array}$ & 0.5 & $\leq 0.7$ & \pm 25 \\
LAI2000 Rsc80 & 0.44 & 0.75 & 19.2 \\
LAI2000 Rsc40 & 0.87 & 0.37 & 5.5 \\
LI191SA Rsc80 & 0.69 & 0.56 & 13.9 \\
LI191SA Rsc40 & 0.89 & 0.33 & 0.0 \\
LAIstep Rsc40 Max1 & 0.89 & 0.33 & -2.0 \\
LAIstep Rsc40 IPG235 & 0.89 & 0.33 & -1.7 \\
LAIadjusted Rsc40adjusted Max1 & 0.90 & 0.31 & 1.3 \\
LAIadjusted Rsc40adjusted IPG235 & 0.90 & 0.31 & 1.6 \\
\hline
\end{tabular}

function simulations, where they are positive for the simulations using LAI measurements. Negative PBIAS values indicate a stronger drying signal.

Differences in PAW are only visible in the period when parameterisation is different (Fig. 5). The year 2013 shows no drought event in spring, where effects would be more obvious. There are small differences in May, where the stepfunction simulation using the Max1 parameters are closer to observations.

However, the abrupt increase to the maximum transpiration rate immediately after LU is rather unrealistic as already shown by the LAI measurements. Unfolding of leaves in nature can happen very quickly, as everybody can observe when spring comes late in the year followed by favourable growth conditions. When spring starts early the full leaf development can take much longer. To account for this and to further improve our model fit, we changed the annual development of LAI and Rsc by using these parameters for manual model calibration, guided by the course of LAI measurements mainly (Fig. 6). Major changes are higher LAI and lower Rsc values at the date of leaf unfolding, i.e. $2 \mathrm{~m}^{2} \mathrm{~m}^{-2}$ and $150 \mathrm{~s} \mathrm{~m}^{-1}$, respectively. LU is estimated with the dynamic approach like in the step-function simulations. This resulted in modelled higher transpiration rates in spring. Nevertheless, the annual course of LAI and Rsc is described more detailed and more similar to the observed LAI dynamics the LAI increase and decline is smoother but also starts a bit earlier in the year and last a bit longer in autumn. Due to that smoother increase in spring the sensitivity to deviations in estimating LU is reduced.

Due to these changes the NSC increased to 0.90 for both Max1 and IPG235 parameter sets. This is the best fit obtained in manual calibration procedure (Table 4). PBIAS values are positive for the adjusted models, which is a slightly too small drying signal. However, the magnitudes of PBIAS and RSR values are smaller than for the step-function simulations, indicating better agreement with observations and lower root mean square errors or residual variations (Moriasi et al., 2007).

\subsubsection{Long-term simulations}

In all simulations shown for the year 2013, the effects on PAW caused by changes in estimated LU are quiet low due to the high soil water contents in spring 2013. Therefore, we applied all simulations for the years 1969-2013, which was the longest meteorological period without missing data. A focus is set to the year 2012, which was characterised by an early drought event in May. Because of missing data there is no complete set of soil water content information available for this year and there is no information about LAI and Rsc for 2012 that can be used to parameterise the hydrological model. So no evaluation of model fit is possible for 2012 or the other years of the period 1969-2013, like it is done for 2013.

To illustrate the effects for the different courses of LAI and Rsc development as well as the estimation of LU, Fig. 7 shows the precipitation, the plant available water and the GWR for the step function and for the adjusted simulations combined with the estimates of LU, i.e. the Max 1 and IPG235 parameter set, respectively. Results in Fig. 7 show the last 2 years from the long-term simulations 1969-2013, mean values for evapotranspiration (ETR) and GWR for the whole period 1969-2013 are presented in Table 5. In 2012 and 2013 as well as for both estimations of LU, the adjusted simulation shows the highest GWR and the step-function simulations result in the lowest GWR. The reason is the change in transpiration in spring, as described due to the different parameterisations of the step function and adjusted course for LAI and Rsc. However, the largest effects on GWR are caused by the different estimation of LU (Fig. 7). In the step-function experiments, GWR is zero in 2012 with both the Max1 and the IPG235 parameterisations of LU. Plant available water is reduced more strongly for the Max1 

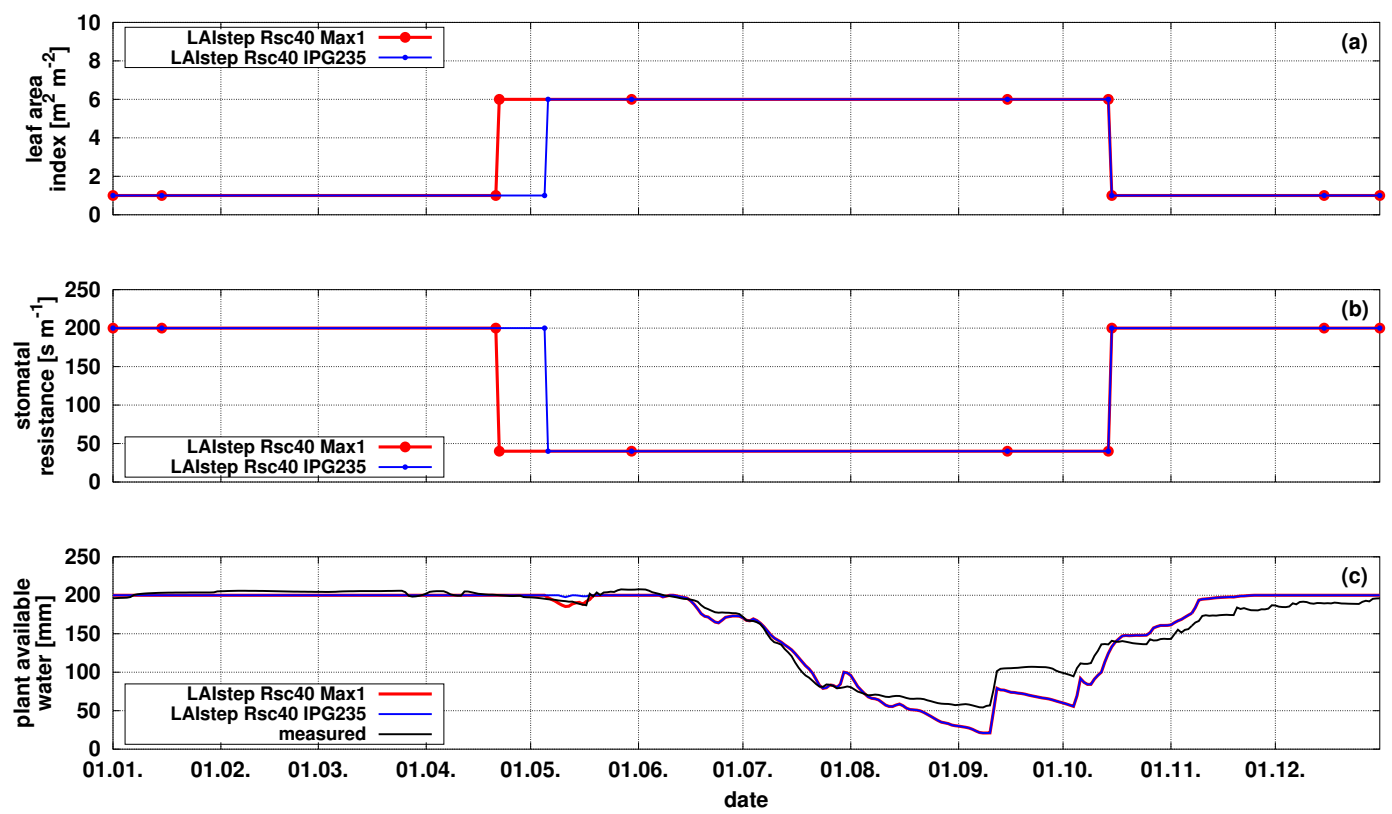

Figure 5. Leaf area index and stomatal resistance parameterised as step function, using maximum and minimum values in the growing season 2013, respectively. LAI is set to 6, stomatal resistance is set to $40 \mathrm{~s} \mathrm{~m}^{-1}$ when LAI is larger than 1 . Leaf unfolding (LU) is determined by the dynamic phenology approach implemented in WaSim, using the Max1 parameterisation and IPG235. Simulations results using the two combinations of LAI and stomatal resistance are shown as plant available soil water, calculated till $1 \mathrm{~m}$ soil depth and compared to values based on soil water content measurements.
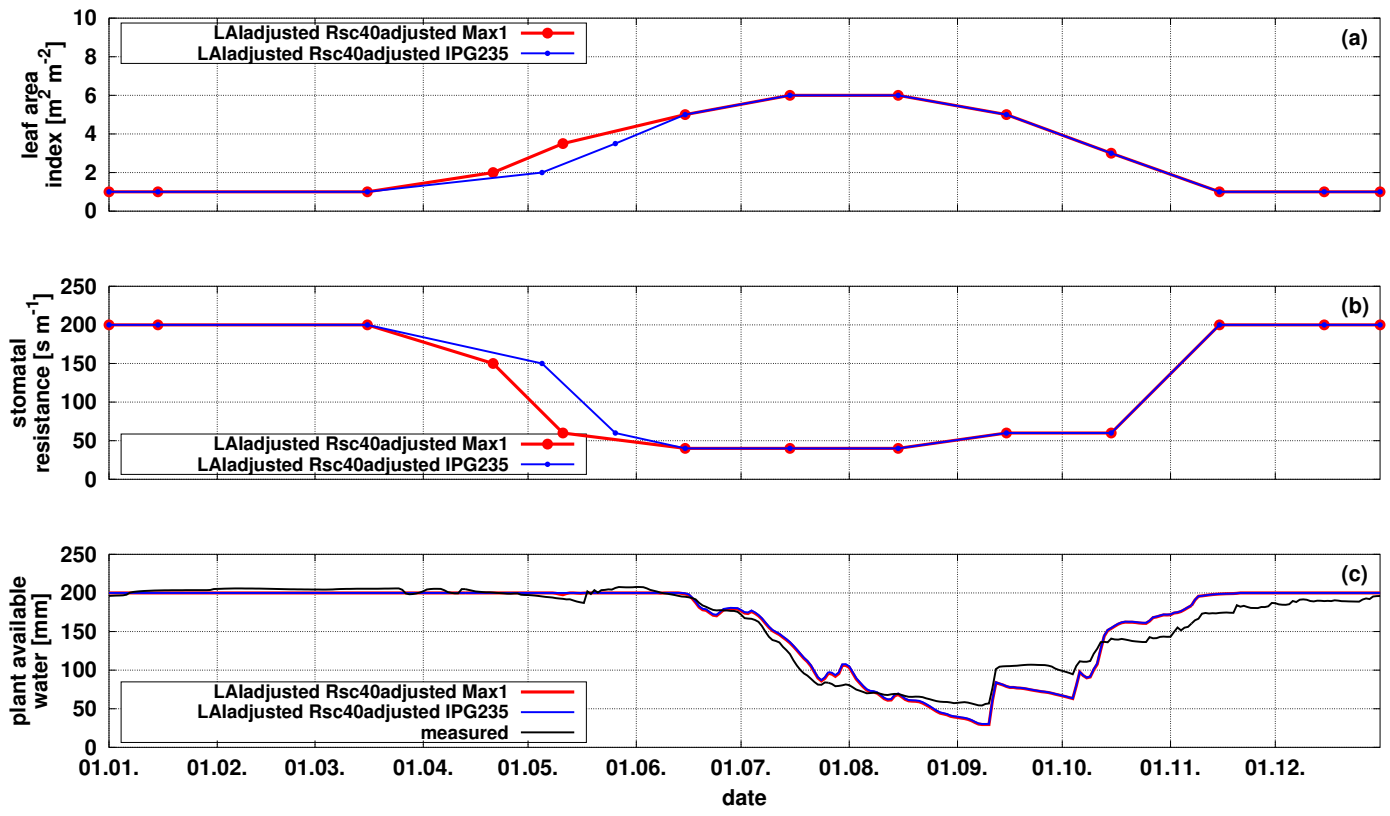

Figure 6. Leaf area index and stomatal resistance as parameterised from adjusted values for 2013. Maximum of leaf area index is set to 6, minimum of stomatal resistance is set to $40 \mathrm{~s} \mathrm{~m}^{-1}$. Leaf unfolding (LU) is determined by the dynamic phenology approach implemented in WaSim, using the Max1 and IPG235parameterisation. The annual course of leaf area index and stomatal resistance is orientated on measurements for leaf area and used as calibration parameter for stomatal resistance. Simulations results using the two combinations of leaf area index and stomatal resistance are shown as plant available soil water, calculated till $1 \mathrm{~m}$ soil depth and compared to values based on soil water content measurements. 

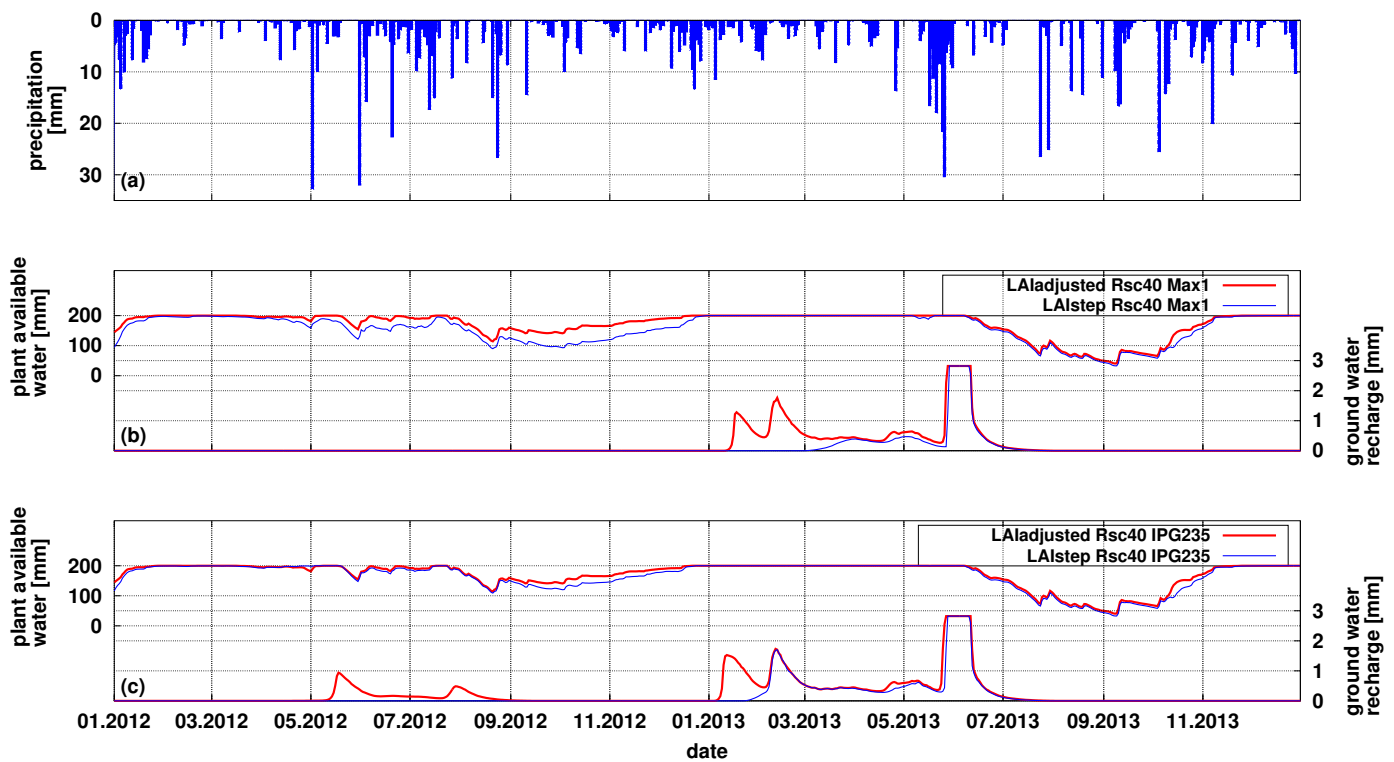

Figure 7. Measured daily precipitation (a). Plant available water and ground water recharge as simulated for the step function and adjusted course for leaf area index and stomatal resistance, using the leaf unfolding (LU) parameters Max1 (b) and IPG235 (c) for simulating LU. The parameterisation for poplar is equal for 2012 and 2013, i.e. the same vegetation hydrological modelled driven by different weather conditions, i.e. a drier year 2012 with an earlier dry period in May.

parameterisation, due to the early start of the growing season. However, this early LU fits better to the observations in Reiffenhausen. For the adjusted simulations, GWR in 2012 is only zero for the Max 1 parameterisation. For the year 2012 data of the matrix potential (tensiometer measurements) in 20,60 and $120 \mathrm{~cm}$ soil depth are available. These data show a drought period in May 2012, where the tensiometers in $20 \mathrm{~cm}$ soil depth run out the measuring range; i.e. a matrix potential was lower than about $-800 \mathrm{hPa}$. Starting from May 2012, the tensiometers in $60 \mathrm{~cm}$ and $120 \mathrm{~cm}$ soil depth indicated a consistent drying signal (not shown). Additionally, the poplar SRC in 2012 is younger and therefore less water demanding than the poplar SRC parameterised in the model, applied for these analyses. This indicates that GWR after May 2012 is very unlikely in these simulations.

The parameterisation using the adjusted course for LAI and Rsc, based on the measured course of LAI, in combination with the Max1 parameterisation for LU, calibrated at local observations, seems to be the most realistic model simulation (LAIadjusted Rsc40 Max1). By comparing all four model parameter combinations shown in Fig. 7, one can switch completely from GWR present in 2012 to absent.

Table 5 summarises the ETR and GWR for all simulations, averaged over all years for the period 1969-2013, as well as for the five driest and five wettest years of this period. GWR averaged over all years varies from 80 to $145 \mathrm{~mm} \mathrm{yr}^{-1}$ depending on the approximation of the annual course of LAI and Rsc and the estimation of LU. The ratio of maximum and minimum of the all year averages of GWR for the different simulations is approx. 1.8. This factor is approx. 3 for the five driest years and approx. 1.7 for the five wettest years, showing that especially the model results for dry years are sensitive to the parameterisations used.

\section{Discussion}

Not all necessary model parameters for WaSim could be measured in detail. One example is the implemented assumption on rooting depth which was measured in 2012, and was set to $1 \mathrm{~m}$, which is comparable to the commonly used values presented in Raissi et al. (2009).

Measuring Rsc in the field is rather challenging. For hydrological modelling we are interested in more theoretically minimum values, indicating optimal transpiration. These conditions are hardly found in reality. In addition, the measurements are affected by soil water availability and rapidly changing atmospheric conditions. Breuer et al. (2003) summarised values for minimal stomatal resistance for various plants. Values for Populus clones (Populus grandidenata, P. tremula and $P$. tremuloides) range from 102 to $400 \mathrm{~s} \mathrm{~m}^{-1}$. Our measured minimum of Rsc for poplar clone Max1 (Populus nigra $\times$ Populus maximowiczii) is lower: $80 \mathrm{~s} \mathrm{~m}^{-1}$. Yet we needed to further reduce Rsc to $40 \mathrm{~s} \mathrm{~m}^{-1}$ for matching the observed soil water contents. On the one hand, the low observed minimum of $80 \mathrm{~s} \mathrm{~m}^{-1}$ shows that specific measurements of Rsc are helpful. On the other hand, the measurements of Rsc were still too high to produce plausible results with WaSim. One might interpret the reduction of Rsc from 80 to $40 \mathrm{~s} \mathrm{~m}^{-1}$ as a shift from the often reported iso- 
Table 5. Precipitation $\left(\mathrm{mm} \mathrm{yr}^{-1}\right)$, total evapotranspiration (ETR) and ground water recharge (GWR) for the period 1969-2013. Simulations are shown for the step-function simulation and the adjusted course for leaf area index and stomatal resistance, using the leaf unfolding (LU) according to the Max1 and IPG235 parameter set for simulating LU. The parameterisation for poplar is equal to that derived for 2013 for the whole period, i.e. the same vegetation hydrological modelled driven by different weather conditions. Values are summed up for all years (1969-2013) of the period and for the five driest and five wettest years, respectively.

\begin{tabular}{lrrrrrr}
\hline & $\begin{array}{r}\text { ETR } \\
\text { (all years) }\end{array}$ & $\begin{array}{r}\text { ETR } \\
\text { (five driest) }\end{array}$ & $\begin{array}{r}\text { ETR } \\
\text { (five wettest) }\end{array}$ & $\begin{array}{r}\text { GWR } \\
\text { (all years) }\end{array}$ & $\begin{array}{r}\text { GWR } \\
\text { (five driest) }\end{array}$ & $\begin{array}{r}\text { GWR } \\
\text { (five wettest) }\end{array}$ \\
\hline $\begin{array}{l}\text { Precipitation } \\
\text { LAIstep }\end{array}$ & 676.7 & 500.4 & 896.6 & 676.7 & 500.4 & 896.6 \\
$\begin{array}{l}\text { Rsc40 Max1 } \\
\text { LAIstep }\end{array}$ & 527.8 & 487.1 & 533.6 & 79.7 & 23.2 & 140.2 \\
$\begin{array}{l}\text { Rsc40 IPG235 } \\
\text { LAIadjusted }\end{array}$ & 488.5 & 463.0 & 482.6 & 105.0 & 37.9 & 170.4 \\
$\begin{array}{l}\text { Rsc40adjusted Max1 } \\
\text { LAIadjusted }\end{array}$ & 484.1 & 460.8 & 477.9 & 107.1 & 41.3 & 173.9 \\
Rsc40adjusted IPG235 & 425.9 & 424.4 & 411.7 & 144.7 & 68.1 & 232.9 \\
\hline
\end{tabular}

hydric behaviour of poplar clones (Tardieu and Simonneau, 1998) to a more anisohydric behaviour. But the diurnal or seasonal variations of leaf water potential that are characteristic for anisohydric plants are not expressed by the Rsc value in WaSim, which represents the minimal resistance for a state when plants are fully supplied with water. The reduction of transpiration in drought stress situations is done in a different way in WaSim. Furthermore, there are also more drought tolerant, anisohydric water use strategies reported from greenhouse experiments for poplar clones (Ceulemans et al., 1988; Larchevêque et al., 2011). Schmidt-Walter et al. (2014) reported also a poor stomatal control of water loss estimated from field measurements of a poplar SRC.

LAI measurements show a systematic difference between the two measurement devices, whereas LI191SA seems to overestimate LAI taking the destructive method as a reference. In situ measurements of LAI are helpful to determine the maximum value, but differences due to the different estimation methods including underlying assumptions should be considered. The annual development of LAI is indispensable information that is needed to adjust and improve the model parameterisation of annual course. The measured LAI development represents local conditions and is therefore valid for the measurement site and time period only. Approximations of seasonal course are advisable to enable the transferability to other sites and years. A crucial factor is LU, which determines the start of LAI increase. Determination of this date requires the definition of phenological stages. Various models are available to describe LU, some are based on air temperature, soil temperature, photoperiod, day length or radiation. All models have to be calibrated for the specific plant species. There is also evidence that local conditions like latitude or altitude of observations are influencing the calibration of the phenological model. Furthermore, the derivation of parameters for the phenological model will depend on the observed data, e.g. the detection of extremely early or late
LU as well as the climate data, which has to be appropriate for the observed site. For poplar clone Max1 we could not find parameter sets in literature, so we used for comparison the IPG235 parameters of Menzel (1997) for Populus tremula, which is better investigated. The period of parameter adjustment used by Menzel (1997) is 1959-1993 and it is based on several phenological stations, whereas our derived parameters are based on 2 years at one site. However, these 2 years show a wide variability in LU. The parameters from Menzel (1997) should be generally more valid, because of the higher number of observations. Yet the use of IPG235 parameters resulted in an underestimation of observed variability, compared to the observations for Populus tremula in Tharandt. Differences between IPG235 and Max1 also show the importance of parameterisations for local site conditions and specific species. Comparing the parameter sets presented in Table 1 these effects become evident.

Especially threshold temperatures for chilling and forcing units, $T_{0}$ and $T_{1}$, vary more widely between IPG235 and Max1. Due to this wider range, the model is able to describe extreme values and therefore a higher variability of LU, which was observed in our calibration years 2012 and 2013. We evaluated our parameter set to observations of the poplar SRC Reiffenhausen in 2014 and the poplar SRC Großfahner (2012-2014), which was planted with the same clone and in the same year like Reiffenhausen. The differences for LU between observations and the Max 1 model set up are low and within the observed variability. The use of IPG235 parameters for the Max 1 clone, which is a common procedure when specific values are missing, can result in large deviations as shown for GWR, especially in the year 2012 with the drought period in spring.

The source of temperature data also influences the parameters derived for phenological models as well as the results obtained by applying these parameter sets. We compared the estimated DOY of LU derived with local temperature 
measurements with estimated DOY derived with temperatures of the nearest DWD stations. For Reiffenhausen, with the nearest DWD station Göttingen, we additionally tested an altitude correction using the vertical temperature gradient of $-0.0065^{\circ} \mathrm{C} \mathrm{m}^{-1}$ to account for $158 \mathrm{~m}$ altitude difference between Göttingen (167 m a.s.1.) and Reiffenhausen (325 m a.s.1.). Deviations in DOY of LU are small when using the DWD temperature instead of the local measurements. Interestingly, the altitude correction of temperature increases differences in DOY of LU compared to observations. The reason could be the often occurring thermal inversion, when the air temperature in Reiffenhausen is higher than in Göttingen, so that implemented altitude reduction of temperature increases the differences even more, due to that also the differences of the estimated DOY of LU increase. The effects of the altitude correction are larger for the Max1 than for the IPG235 parameter set, because our model is more sensitive to extreme values due to higher $T_{0}$ and lower $T_{1}$ temperatures. This shows the importance of applying the local temperatures, associated with the phenological observations, to calibrate and use the temperature-dependent phenological models. The use of local temperatures improves the estimation of LU and better represents interannual variability.

According to the criteria of Moriasi et al. (2007), the hydrological model results, using measured values of LAI and Rsc (start and development of LU is implemented), are satisfactory only for the simulation LI191SA with Rsc $=80 \mathrm{~s} \mathrm{~m}^{-1}$. The simulation using the LAI values from the LAI2000 does not satisfy the recommended criteria (Table 4). However, the model produces better agreement with observations when Rsc minima of $40 \mathrm{~s} \mathrm{~m}^{-1}$ are used with any LAI data. The reduction of Rsc is a suitable way to simulate the observed soil water conditions. An increase of LAI could lead to lower soil water contents as well, but it is also affecting soil evaporation and interception evaporation. Additionally, larger values for LAI, necessary to minimise the model deviations to measurements, have to be unrealistically high for the poplar SRC investigated here. When using a Rsc minimum of $40 \mathrm{~s} \mathrm{~m}^{-1}$ together with measured LAI the model evaluation is good for the year 2013, reaching NSC values of 0.87 and 0.89 for the LAI2000 and LI191SA simulations, respectively.

Data of such intense measurement campaigns are not available for all sites were hydrological modelling should be done. Therefore literature values, typically providing just maximum or minimum values for LAI and Rsc, are used and the annual course has to be modelled. The question of transferability of these values to different sites, years or even species has to be solved. The applied step function is the simplest approximation of the annual course for LAI and Rsc. These simulations also pass the recommended criteria for a satisfactory model performance (Table 4).

For the year 2013 the best model fit could be obtained by the adjusted annual courses for LAI and Rsc. They are based on the observed course and maximum values of LAI measurements.

The weather regime and therefore the development of soil water conditions are not suitable in 2013 to show the effects of different estimates for the start of LU in spring. Drought conditions started after July 2013; therefore, we performed scenario simulation by transferring the vegetation parameterisation for 2013 to the weather regime of 2012. This year was characterised by a drought period in spring. Consequently, the effects of different estimates of DOY of LU are pronounced. The adjusted simulations using the IPG235 parameters to estimate LU, i.e. later LU by approx. 30 days in 2012, show GWR in 2012. Due to the delayed start of the growing season, the drought stress in spring is not reproduced by the model, leading to wetter soil conditions which favours percolation and rewetting and finally enlarges GWR (Fig. 7). The tensiometer measurements available for 2012 suggest that GWR is rather unlikely for this year. The adjusted simulation using the Max1 parameters for LU and both stepfunction simulations (Max1 and IPG235) result in zero GWR for the year 2012. However, the strongest simplification of the course of LAI and Rsc, i.e. the step function, shows the lowest GWR for 2013 and for the long-term simulations (Table 5).

In Fig. 7 the effects of the different simulations on GWR are presented for the years 2012 and 2013, which are characterised by rather different weather regimes. Whereas a realistic description of LAI and Rsc seems to be less important in 2013 , it is even more essential in 2012, showing the importance of distinct spatial and temporal characteristics for local modelling.

We performed a long-term simulation, by keeping the parameterisation for the vegetation constant for the period 1969-2013 to account for the effects of climate variability. This is a more theoretical scenario, because it accounts for changes in climate forcing only. In reality also the vegetation characteristics are changing over the years, as well as soil properties on a longer timescale, especially for SRC, whereas rotation cultivation is applied, e.g. harvesting and re-sprouting. Particularly the rotation cultivation can reduce extreme drought conditions, when dry years coincide with rotation stages that have a lower water demand. The vegetation parameterised here can be seen as fully developed in hydrological terms, characterised by a large water demand. The simulations here are rather artificial, especially by succeeding dry years when soil water storage is not refilled completely in winter and drought conditions are influencing the following growing season. Nevertheless, the effects caused by different descriptions of vegetation parameterisations are quiet large (Table 5). Especially on a local scale such differences can be important by evaluating effects of land use change, particularly in dry years.

Taking into account that the best model evaluation for 2013 is achieved with the adjusted course of LAI and Rsc, the adjusted simulation using the Max1 phenology param- 
eters seems to be the most reasonable parameterisation. It gives the best fit to the evaluation in 2013 .

\section{Conclusions}

In the context of hydrological analysis of sites with focus on land use change or climate change, an adequate parameterisation of the vegetation cover is important to determine processes like soil evaporation, interception evaporation and transpiration. Sources of model parameters for the vegetation cover are local measurements or scientific literature. The analysis shows simulation uncertainties evolving from the use of model parameters that are derived from (i) non-local measurements or (ii) some appropriate literature values.

Regarding the objective 1 of our study, we showed that LAI, Rsc as well as the beginning and length of growing season are very sensitive parameters when effects of an enhanced cultivation of SRC on local water budget are investigated. In particular, our analysis reveals that correct information about the beginning of the growing season is highly important to obtain correct and acceptable simulation results of evapotranspiration components and GWR. If the start of the growing season is inappropriate, such as shown for the different species as in the IPG235 and Max1 parameterisation (Table 1), the accuracy of other parameters (like LAI and Rsc) plays a minor role. Concerning GWR, LU is the most sensitive parameter. Its parameterisation is particularly important when interannual variations and hydrological extreme conditions are on focus.

The implementation of locally measured vegetation parameters for hydrological modelling has both advantages and drawbacks. Measurements are expensive, time-consuming and also not always feasible. In such cases the use of appropriate literature values and transposition of adjacent observations is necessary and common practice.

The present study displays that locally measured LAI are suitable information for hydrological simulations. The comparisons between locally measured and adjusted parameter sets reveal that simulation results are less affected by other model parameters, like Rsc or LU, when using adjusted parameters of LAI.

Opposite results appear for Rsc. Simulation results differ significantly when site-specific values of Rsc are available. However, for Rsc the benefit of direct use of local measurements is arguable: minimum has to be reduced within WaSim to produce model results comparable with soil water measurements. In consequence the implementation of Rsc values from literature for hydrological modelling without accompanying measurement data for model evaluation can produce very uncertain results. The analyses illustrate that the locally adjusted vegetation parameterisation gives the best model fit. Additionally, the adjusted course of LAI and Rsc is less sensitive to different estimates for $\mathrm{LU}$, due to a slower increase in spring compared to a step-functional annual course. How- ever, the adjusted courses are also approximations and not a distinct measurement, and are therefore more generally valid for different sites and years, than a direct use of measured parameters.

For the land use poplar SRC there are certain years where the modelled GWR is reduced to zero, like in the year 2012 (Fig. 7). Different parameterisations for vegetation characteristics are influencing modelled GWR for those years producing a wide range from GWR present or completely absent.

Hydrological models are often used to analyse effects of climate and land use changes on spatial and temporal scale becoming smaller and smaller. Approximations in the description of vegetation, a lack of local information (also soil and climate description), the transfer of inappropriate parameters and deficiency in model formulation can cause large differences in simulation results. To account for small-scale and local effects of land use change, a more detailed descriptions of sites and processes are necessary to capture the spatial and temporal variability of effects. In particular, the extremes are often underestimated when the description of site and processes are insufficient.

\section{The Supplement related to this article is available online at doi:10.5194/hess-19-3457-2015-supplement.}

Acknowledgements. The work was funded by the German Federal Ministry of Education and Research (BMBF) and is part of the BEST-Research Framework (http://www.best-forschung.de), we gratefully acknowledge this support.

We give our special thanks to D. Fellert and H. Kreilein for valuable advices and assistance in handling the meteorological equipment; to D. Böttger for his assistance in field work, to J. Sauer, H. Wendler and G. Kalberlah for their assistance in measurements. Thanks to A. Knohl for the fruitful discussions and for the help in solution of research problems. Special thanks to J. Schulla for advising in all WaSim questions arose during the study, solving problems and providing new model versions.

This open-access publication was funded by the University of Göttingen.

Edited by: N. Romano

\section{References}

Aronsson, P. G., Bergström, L. F., and Elowson, S. N. E.: Long-term influence of intensively cultured short-rotation Willow Coppice on nitrogen concentrations in groundwater, J. Environ. Manage., 58, 135-145, 2000.

Baum, S., Weih, M., and Bolte, A.: Stand age characteristics and soil properties affect species composition of vascular plants in short rotation coppice plantations, 7, 51-71, 2012. 
Bernhofer, C.: Institut für Hydrologie und Meteorologie, Professur Meteorologie: Exkursions- und Praktikumsführer Tharandter Wald Material zum "hydrologisch-meteorologischen Feldpraktikum," Techn. Univ., Dresden, 2002.

Blume, H.-P., Brümmer, G. W., Horn, R., Kandeler, E., KögelKnabner, I., Kretzschmar, R., Stahr, K., Thiele-Bruhn, S., Welp, G., and Wilke, B.-M.: Lehrbuch der Bodenkunde, Springer, 552 pp., 2010.

Breda, N. J.: Ground-based measurements of leaf area index: a review of methods, instruments and current controversies, J. Exp. Bot., 54, 2403-2417, 2003.

Breuer, L., Eckhardt, K., and Frede, H.-G.: Plant parameter values for models in temperate climates, Ecol. Model., 169, 237-293, 2003.

Broeckx, L. S., Verlinden, M. S., Berhongaray, G., Zona, D., Fichot, R., and Ceulemans, R.: The effect of a dry spring on seasonal carbon allocation and vegetation dynamics in a poplar bioenergy plantation, GCB Bioenergy, 6, 473-487, 2013.

Cannell, M. G. R. and Smith, R. I.: Thermal time, chill days and prediction of budburst in Picea sitchensis, J. Appl. Ecol., 20, 951963, 1983.

Ceulemans, R., Impens, I., and Imler, R.: Stomatal conductance and stomatal behavior in Populus clones and hybrids, Can. J. Bot., 66, 1404-1414, 1988.

Chmielewski, F.-M., Heider, S., Moryson, S., and Bruns, E.: International Phenological Observation Networks: Concept of IPG and GPM, in Phenology: An Integrative Environmental Science, 137-153, Springer, 2013.

Djomo, S. N., Kasmioui, O., and Ceulemans, R.: Energy and greenhouse gas balance of bioenergy production from poplar and willow: a review, GCB Bioenergy, 3, 181-197, 2011.

Don, A., Osborne, B., Hastings, A., Skiba, U., Carter, M. S., Drewer, J., Flessa, H., Freibauer, A., Hyvönen, N., Jones, M. B., Lanigan, G. J., Mander, Ü., Monti, A., Djomo, S. N., Valentine, J., Walter, K., Zegada-Lizarazu, W., and Zenone, T.: Land-use change to bioenergy production in Europe: implications for the greenhouse gas balance and soil carbon, GCB Bioenergy, 4, 372391,2012

Hartmann, L., Richter, F., Busch, G., Ehret, M., Jansen, M., and Lamersdorf, N.: Etablierung von Kurzumtriebsplantagen im Rahmen des Verbundprojektes BEST in Süd-Niedersachsen und Mittel-Thüringen - Standorteigenschaften und anfängliche Erträge, Forstarchiv, 134-150, 2014.

International Phenological Gardens of Europe: IPG, Phasen, available at: http://ipg.hu-berlin.de/ipg/faces/list_phases.xhtml (last access 9 September 2014), 2014

Jonckheere, I., Fleck, S., Nackaerts, K., Muys, B., Coppin, P., Weiss, M., and Baret, F.: Review of methods for in situ leaf area index determination: Part I, Theories, sensors and hemispherical photography, Agric. For. Meteorol., 121, 19-35, 2004.

Kalberlah, G.: Wurzelverteilungsmuster einer PappelKurzumtriebsplantage in Südniedersachsen, Master Thesis, Georg-August-Universität Göttingen, Göttingen, 16-22, 2013.

Larchevêque, M., Maurel, M., Desrochers, A., and Larocque, G. R.: How does drought tolerance compare between two improved hybrids of balsam poplar and an unimproved native species?, Tree Physiol., 31, 240-249, 2011.

Lasch, P., Kollas, C., Rock, J., and Suckow, F.: Potentials and impacts of short-rotation coppice plantation with aspen in East- ern Germany under conditions of climate change, Reg. Environ. Change, 10, 83-94, 2010.

LGLN - Landesbetrieb Landesvermessung und Geobasisinformation: Digitale Geländemodelle - DGM - ATKIS, 2013.

LI-CO179 pp., 1992.

Lorenz, K. and Müller, J.: Ergebnisse zur Nettoprimärproduktion von mit biologisch geklärtem Abwasser bewässerten Pappeln und Weiden im Kurzumtrieb, Landbauforsch., Appl. Agric. For. Res., 63, 307-320, 2013.

Menzel, A.: Phänologie von Waldbäumen unter sich ändernden Klimabedingungen: Auswertung der Beobachtungen in den internationalen phänologischen Gärten und Möglichkeiten der Modellierung von Phänodaten, Frank, 147 pp., 1997.

Menzel, A.: Trends in phenological phases in Europe between 1951 and 1996, Int. J. Biometeorol., 44, 76-81, 2000.

Moriasi, D. N., Arnold, J. G., Van Liew, M. W., Bingner, R. L., Harmel, R. D., and Veith, T. L.: Model evaluation guidelines for systematic quantification of accuracy in watershed simulations, Trans ASABE, 50, 885-900, 2007.

Octave community: GNU Octave, available at: www.gnu.org/ software/octave/ (last access: 30 July 2015), 2012.

Petzold, R., Wahren, A., and Feger, K.-H.: Steuerungsoptionen des Wasser- und Stoffhaushalts auf Landschaftsebene durch den Anbau von Kurzumtriebsplantagen - ein Forschungsansatz, in Bodenschutz in Europa - Ziele und Umsetzung, 6, 91-96, Marktredwitzer, available at: http://boku.forst.tu-dresden.de/pdf/ petzold_wahren_feger_Steuerungsoptionen.pdf (last access: 30 July 2015), 2010.

Raissi, F., Müller, U., and Meesenburg, H.: Geofakten 9 Ermittlung der effektiven Durchwurzelungstiefe von Forststandorten, Red. Geofakten Landesamt Für Bergbau Energ. Geol. Hann., (4. Auflage), available at: http://www.lbeg.niedersachsen.de (last access: 30 July 2015), 2009.

R Development Core Team: RStudio for Windows, R Foundation for Statistical Computing, Vienna, Austria, available at: http:// www.R-project.org (last access: 30 July 2015), 2011.

Rutter, A. J., Kershaw, K. A., Robins, P. C., and Morton, A. J.: A predictive model of rainfall interception in forests, 1 . Derivation of the model from observations in a plantation of Corsican pine, Agric. Meteorol., 9, 367-384, 1971.

Schmidt-Walter, P. and Lamersdorf, N.: Biomass Production with Willow and Poplar Short Rotation Coppices on Sensitive Areas - the Impact on Nitrate Leaching and Groundwater Recharge in a Drinking Water Catchment near Hanover, Germany, BioEnergy Res., 5, 546-562, 2012.

Schmidt-Walter, P., Richter, F., Herbst, M., Schuldt, B., and Lamersdorf, N. P.: Transpiration and water use strategies of a young and a full-grown short rotation coppice differing in canopy cover and leaf area, Agric. For. Meteorol., 195-196, 165-178, 2014.

Schulla, J.: Hydrologische Modellierung von Flussgebieten zur Abschätzung der Folgen von Klimaänderungen, ETH Zürich, doi:10.3929/ethz-a-001763261, 1997.

Schulla, J. and Jasper, K.: Model Description WaSiM-ETH, Inst. Atmospheric Clim. Sci. Swiss Fed. Inst. Technol. Zür, available at: http://www.wasim.ch/downloads/doku/wasim/wasim_2007_ en.pdf (last access: 30 July 2015), 2013.

Spank, U., Schwärzel, K., Renner, M., Moderow, U., and Bernhofer, C.: Effects of measurement uncertainties of meteorological data 
on estimates of site water balance components, J. Hydrol., 492, 176-189, 2013.

Surendran Nair, S., Kang, S., Zhang, X., Miguez, F. E., Izaurralde, R. C., Post, W. M., Dietze, M. C., Lynd, L. R., and Wullschleger, S. D.: Bioenergy crop models: descriptions, data requirements, and future challenges, GCB Bioenergy, 4, 620-633, 2012.

Tardieu, F. and Simonneau, T.: Variability among species of stomatal control under fluctuating soil water status and evaporative demand: modelling isohydric and anisohydric behaviours, J. Exp. Bot., 49, 419-432, 1998.

Van Genuchten, M. T.: A closed-form equation for predicting the hydraulic conductivity of unsaturated soils, Soil Sci. Soc. Am. J., 44, 892-898, 1980.
Volkert, E. and Schnelle, F.: Arboreta Phaenologica: Mitteilung der Arbeitsgemeinschaft Internationaler Phänologischer Gärten, Erläut. Zur Beob., Phänologischen Termins Blattentfaltung Bei Popolus Tremula, 7, 5 pp., 1966.

Watson, D. J.: Comparative physiological studies on the growth of field crops: I. Variation in net assimilation rate and leaf area between species and varieties, and within and between years, Ann. Bot., 11, 41-76, 1947.

Zambrano-Bigiarini, M.: hydroGOF: Goodness-of-fit functions for comparison of simulated and observed hydrological time series, available at: http://CRAN.R-project.org/package= hydroGOF (last access: 30 July 2015), 2014. 